Article

\title{
Optical Design of a Miniaturized Airborne Push-Broom Spectrometer
}

\author{
Yang Wang ${ }^{1} \mathbb{C}$, Zhiyuan $\mathrm{Gu}^{2, *}{ }^{2}$, Xiangyue Meng ${ }^{3}$, Lei Zhang ${ }^{1}$ and Yuegang Fu ${ }^{1}$ \\ 1 School of Opto-Electronic Engineering, Changchun University of Science and Technology, \\ Changchun 130022, China; wangyang@cust.edu.cn (Y.W.); zhangl@cust.edu.cn (L.Z.); fuyg@cust.edu.cn (Y.F.) \\ 2 Changchun Institute of Optics, Fine Mechanics and Physics, Chinese Academy of Sciences, \\ Changchun 130033, China \\ 3 Research and development center, Zhejiang Sunyu Optics Co. Ltd., Yuyao 315400, China; \\ mengxiangyue1314@163.com \\ * Correspondence: zhiyuan.gu@hotmail.com; Tel.: +86-187-4302-0263
}

Received: 23 February 2020; Accepted: 7 April 2020; Published: 10 April 2020

check for updates

\begin{abstract}
Combining the requirements of spectrometers for unmanned aerial vehicle platforms, a miniaturized airborne wide-angle push-broom imaging spectrometer with an Offner configuration is designed. The system comprises an objective lens and an Offner-type spectrometer with a spectral range of 400 1000 $\mathrm{nm}$ and a spectral resolution of $15 \mathrm{~nm}$. The objective lens and Offner spectrometer are designed in isolation before integration. The front objective lens is an inverted telephoto with a focal length of $13 \mathrm{~mm}$, a relative aperture of $1 / 4.5$, and a field of view of $54^{\circ}$. The frequency of the convex grating in the Offner configuration is $102 \mathrm{LP} / \mathrm{mm}$, and the dispersion width is $2.6 \mathrm{~mm}$. The modulation transfer function of the integrated system is greater than 0.4 at the Nyquist frequency in all spectral bands. To estimate the volume and weight of the system, a preliminary optical-mechanical design scheme is given in this paper. The entire spectrometer has a volume of $130 \times 80 \times 120 \mathrm{~mm}$ and is less than $3 \mathrm{~kg}$, which realizes the miniaturization design of the imaging spectrometer with a wide field of view for unmanned aerial vehicle platforms.
\end{abstract}

Keywords: spectrometer; UAV; optical design; SNR; Offner; miniaturization

\section{Introduction}

The spectrometer appeared in the late 1970s and it is a breakthrough in the remote sensing field [1]. Since its birth, it has been favored for its wide application range, which includes military reconnaissance, surveys of agriculture, forestry monitoring, and mineral resource exploration [2-5]. With the rapid development of unmanned aerial vehicles (UAVs) and small satellite technology, the demand for miniaturized spectrometers has become increasingly intense [6-10]. We have investigated some typical small commercial spectrometers suitable for UAVs. For example, the AFX10 of Specim Spectral Imaging Ltd. for visible and near-infrared (VNIR) bands, which has a spectral resolution of $5.5 \mathrm{~nm}$, a field of view $(F O V)$ of $38^{\circ}$, a volume of $131 \times 152 \times 202 \mathrm{~mm}$, and a weight of $2.5 \mathrm{~kg}$. Hyspex's VNIR-1800 has a spectral resolution of $3.26 \mathrm{~nm}$, an $F O V$ of $17^{\circ}$, a volume of $390 \times 99 \times 150 \mathrm{~mm}$, and a weight of $5 \mathrm{~kg}$. A spectrometer with a wide $F O V$ has a larger imaging width, which could improve the efficiency of the push-broom. The spectral resolution of these commercial spectrometers is already very high, but the FOV and miniaturization design still need to be improved to meet different application needs.

The traditional spectrometer with grating or a prism has the disadvantage of spectral line curvature. The Offner spectrometers have been widely developed for their miniaturization with better image quality and spectral resolution, which consist of three spherical concentric elements (a convex grating and two concave mirrors) that simultaneously achieve aberration correction and spectral separation. 
The Offner spectrometer not only realizes a long slit length and a low $f$-number with a miniaturized structure, but also solves the problems of "smile" and "keystone" distortions [11-17].

According to the application requirements, combined with the development status of the airborne push-broom spectrometers, a miniaturized Offner-type spectrometer with a wide $F O V$, which can be integrated into a UAV platform or other aircraft, is designed in this paper. The objective lens and Offner spectrometer are designed in isolation before integration based on the calculation of the signal-to-noise ratio (SNR). A preliminary optical-mechanical design scheme is also discussed in this paper.

\section{System Specification}

\subsection{Specifications of the Spectrometer}

Our project uses the F-40 fixed-wing surveying and mapping UAV of Easy Fly Ltd. The maximum mission payload of the F-40 UAV is $6 \mathrm{~kg}$, the maximum flight speed is $100 \mathrm{~km} / \mathrm{h}$, and the maximum flight altitude is $3.5 \mathrm{~km}$. The positioning and orientation system uses PPOI-A28 from Leador Company, which adopts a customized integrated structure with a volume of $150 \times 140 \times 120 \mathrm{~mm}$ and a weight less than $2.5 \mathrm{~kg}$. Based on the project requirements and the UAV platform, the specifications of the spectrometer were determined and are shown in Table 1. A wide FOV, a broad spectral range, and miniaturization should be achieved simultaneously.

Table 1. Specifications of the spectrometer. The signal-to-noise ratio (SNR) is meaningful only at a given reference radiance, which is provided by the application.

\begin{tabular}{cccccc}
\hline Spectral Range & $\begin{array}{c}\text { Spectral } \\
\text { Resolution }\end{array}$ & $\begin{array}{c}\text { Spatial } \\
\text { Resolution }\end{array}$ & $\begin{array}{c}\text { Coverage } \\
\text { Width }\end{array}$ & $\begin{array}{c}\text { Total } \\
\text { Weight }\end{array}$ & SNR \\
\hline $0.4 \sim 1.0 \mu \mathrm{m}$ & $15 \mathrm{~nm}$ & $0.5 \mathrm{~m} @ 1 \mathrm{~km}$ & $1 \mathrm{~km} @ 1 \mathrm{~km}$ & $<3 \mathrm{~kg}$ & $\geq 100$ \\
\hline
\end{tabular}

\subsection{Optical System Parameters}

The optical system is an important part of the spectrometer, as it determines the performance and weight of the spectrometer. The main parameters of the optical system include focal length $\left(f^{\prime}\right), F O V$, relative aperture $(1 / \mathrm{F})$, and dispersion width of the slit image $(d)$. The FOV angle of the optical system is calculated to be $53.2^{\circ}$ according to the coverage width and flight altitude.

\subsubsection{Sensor Selection and Frame Rate}

The image sensor is the core component of an airborne spectrometer. After researching existing commercial products, we selected the GSENSE2011 CMOS of Gpixel. Its specific parameters are shown in Table 2.

Table 2. The parameters of GSENSE2011 CMOS.

\begin{tabular}{cc}
\hline Parameters & Value \\
\hline Pixel number & $2048 \times 1152$ \\
Pixel size $(\mu \mathrm{m})$ & $6.5 \times 6.5$ \\
Dark Noise $\left(\mathrm{e}^{-}\right)$ & $<6$ \\
Dark Current $\left(\mathrm{e}^{-} / \mathrm{p} / \mathrm{s}\right)$ & $<1$ \\
Maximum frame rate $(\mathrm{fps})$ & 167 \\
\hline
\end{tabular}

According to the spectrometer's instantaneous field of view (iFOV), flight speed (v), and flying altitude $(H)$, the frame frequency of the sensor $(f p s)$ can be calculated, and its expression is as follows:

$$
\frac{1}{f p s}=i F O V \cdot \frac{H}{v}
$$


According to the spatial resolution $(0.5 \mathrm{~m} @ 1 \mathrm{~km})$ in Table 1 , the $i F O V$ is $0.5 \mathrm{mrad}$. When the aircraft's altitude is $1 \mathrm{~km}$ and the speed is $100 \mathrm{~km} / \mathrm{h}$, the fps should be 56 frames, and the corresponding integration time is $0.018 \mathrm{~s}$.

\subsubsection{Focal Length}

The focal length $\left(f^{\prime}\right)$ of the optical system is related to the sensor's pixel size $(p)$, the Ground Sample Distance (GSD), and the flying altitude $(H)$, as shown in Equation (2):

$$
f^{\prime}=\frac{H \cdot p}{G S D}
$$

After calculation, the focal length is $13 \mathrm{~mm}$ when the altitude is $1 \mathrm{~km}$.

\subsubsection{Relative Aperture}

The relative aperture mainly affects the SNR of the spectrometer. The larger the relative aperture is, the higher the SNR of the image is, which is beneficial to obtain high-quality spectral data. However, the aberration is difficult to correct, and the volume and weight are also increased. A small relative aperture will result in a decreased energy in the image and a small SNR. Combining the existing spectrometer, the relative aperture of the front objective lens is determined to be $1 / 4.5$ according to the SNR estimation and the optical design analysis.

\subsubsection{Dispersion Width of the Slit}

A wide dispersion width facilitates an increase in spectral resolution, but the dispersion of energy also reduces the SNR. Although a narrow dispersion width is advantageous for improving the SNR, the positioning accuracy of the secondary spectral filter is required to be much higher. Therefore, the dispersion width of the slit depends on the specifications of the sensor, spectral range, spectral resolution, and SNR.

From Table 1, the spectral resolution of the spectrometer is $15 \mathrm{~nm}$, and the spectral range is 400 1000 nm, which could be divided into 40 channels. For spectral detection, one channel could be extended to 10 rows of pixels, that is, the slit image is expanded to 400 pixels. The dispersion width of the slit $(d)$ could be calculated by:

$$
d=N \times c \times p
$$

where $N$ is the number of spectral channels and $c$ is the number of pixel rows in each channel. According to Table $2, d$ is $2.6 \mathrm{~mm}$.

\section{SNR Calculation}

\section{1. $S N R$}

The SNR of the spectrometer directly affects the subsequent imaging effects. The SNR equation of an optical imaging remote sensor is as follows:

$$
S N R=\frac{S_{e}}{N_{e}}=\frac{S_{e}}{\sqrt{S_{e}+\left(n \sigma_{R}\right)^{2}+n D_{e}}}
$$

where $S_{e}$ is the number of signal electrons; $\sigma_{R}$ is the dark noise; $D_{e}$ is the dark current noise; and $n$ is a coefficient, which is equal to 10 in this paper because 10 rows of pixels are combined in the output of the operating spectrometer. 


\subsection{Signal Electron Number}

The number of signal electrons generated per unit wavelength can be calculated by:

$$
S_{e}(\lambda)=\frac{\pi \lambda \mathrm{A}_{\mathrm{d}} L(\lambda) \tau_{o}(\lambda) D E t_{\mathrm{int}} \eta(\lambda) \Delta \lambda}{4 F^{2} h c}
$$

where $\lambda$ is the wavelength value; $A_{d}$ is the pixel area of the sensor; $L(\lambda)$ is the spectral radiance of the entrance pupil; $\tau_{o}(\lambda)$ is the transmittance of the optical system; $D E$ is the diffraction efficiency of the grating; $t_{\text {int }}$ is the integral time, which is estimated to be $80 \%$ of the integral time calculated from Equation (1); $\eta(\lambda)$ is the quantum efficiency $(Q E)$ of the sensor; $\Delta \lambda$ is the interval of spectral sampling; $\mathrm{F}$ is the $f$-number of the optical system; $h$ is the Planck constant $\left(6.626176 \times 10^{-34} \mathrm{~J} \cdot \mathrm{s}\right)$; and $c$ is the speed of light in a vacuum $[18,19]$.

The spectral radiance of the entrance pupil was calculated by Modtran software, and the calculation conditions were:

1. Altitude: $1 \mathrm{~km}$;

2. Solar zenith angle: $30^{\circ}$;

3. Ground albedo: $30 \%$ (a commonly used remote sensing condition);

4. Atmospheric model: Mid-latitude summer;

5. Boundary temperature $(\mathrm{T}): 300 \mathrm{~K}$; and

6. Aerosol model: Rural aerosol, visibility $23 \mathrm{~km}$.

The spectral radiance curve of the entrance pupil for $0.4 \sim 1.0 \mu \mathrm{m}$ calculated by Modtran is shown in Figure 1.

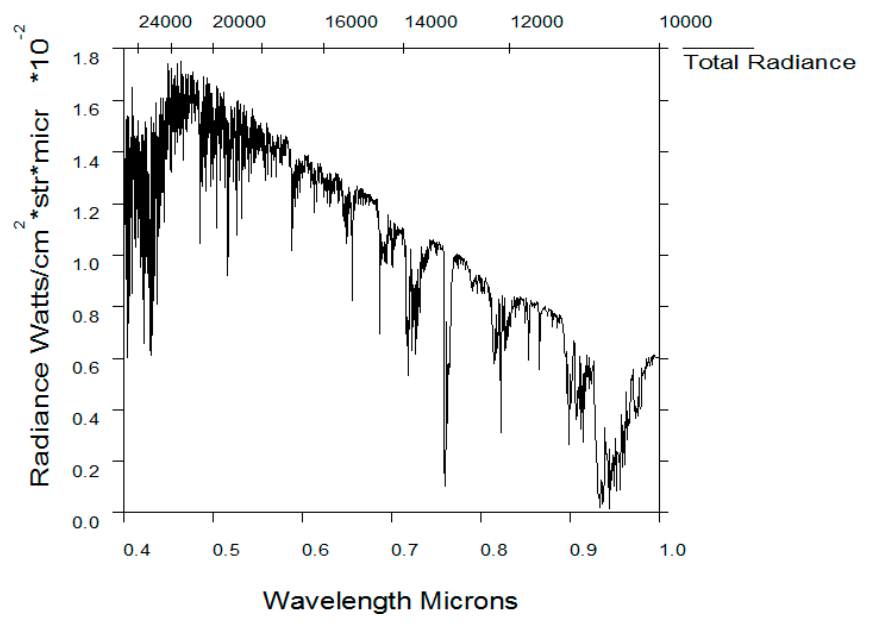

Figure 1. The spectral radiance curve of the entrance pupil.

The diffraction efficiency $(D E)$ of the grating is shown in Figure 2, which is the measured data from grating manufacturers. The quantum efficiency $(Q E)$ of the sensor is shown in Figure 3.

The other values of Equation (5) are shown in Table 3.

Table 3. Relative parameter values for Equation (5).

\begin{tabular}{cc}
\hline Parameters & Value \\
\hline$A_{d}$ & $4.225 \times 10-11 \mathrm{~m}^{2}$ \\
$\tau_{o}(\lambda)$ & 0.85 \\
$t_{\text {int }}$ & $0.014 \mathrm{~s}$ \\
$\Delta \lambda$ & $15 \mathrm{~nm}$ \\
$\mathrm{~F}$ & 4.5 \\
\hline
\end{tabular}




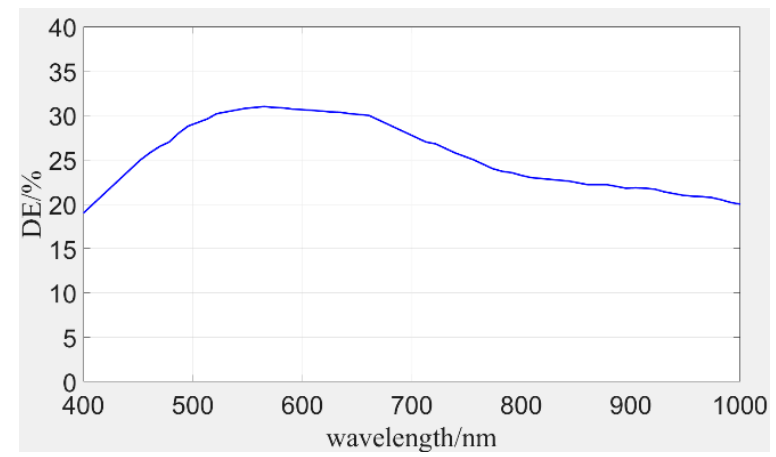

Figure 2. The diffraction efficiency of the grating.

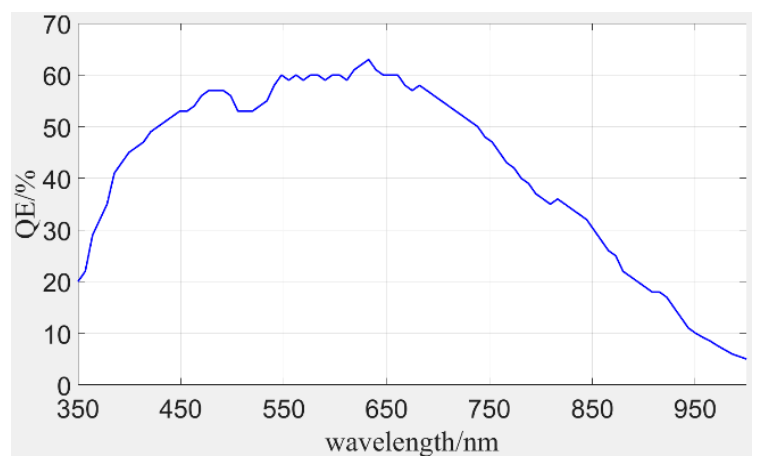

Figure 3. The quantum efficiency of the CMOS.

\subsection{Calculation Results}

By substituting all parameters into Equation (4), the SNR of the full band can be obtained. As shown in Figure 4, the average SNR is 138, and the maximum SNR is 216 at $0.61 \mu \mathrm{m}$. This meets the SNR requirement of the spectrometer shown in Table 1.

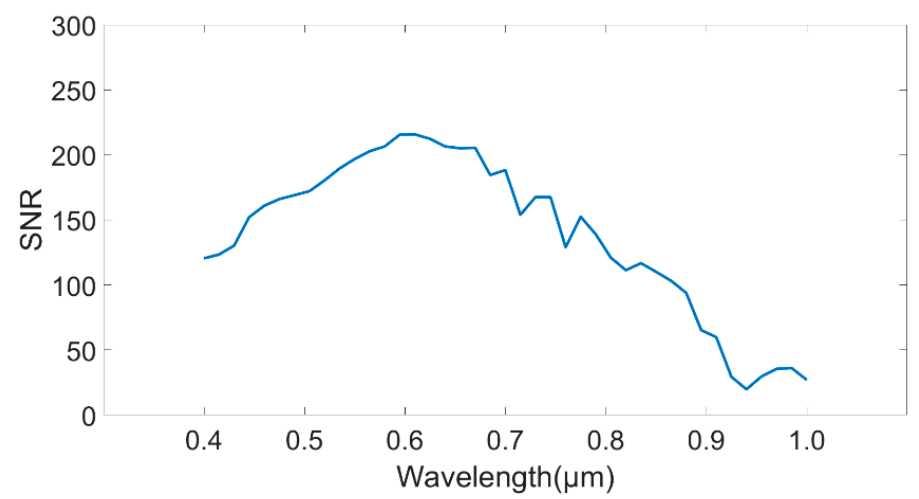

Figure 4. The SNR of the spectrometer in the spectral range of $0.4 \sim 1.0 \mu \mathrm{m}$.

\section{Objective Lens Design}

After analysis and calculation, the optical parameters of the objective lens are determined as shown in Table 4.

The front objective lens is a wide-angle, broad-spectrum optical system. A telecentric optical system should be used to achieve pupil matching with an Offner spectrometer [20]. The optional objective lenses include double Gauss objective, inverted telephoto objective, and fisheye lenses. The double Gauss objective lens is a large-aperture, wide FOV optical system, but it is difficult to achieve image telecentricity with it. Fisheye lenses can achieve very large FOVs, but the distortion is 
difficult to eliminate. The inverted telephoto objective lens has a certain ability to eliminate distortion. By complicating the front group of the inverted telephoto objective lens, the FOV can be enlarged, and the image telecentricity can be formed by using a field lens in front of the focus. Finally, an inverted telephoto is adopted with good corrections for aberrations, especially chromatic aberrations. The final design result of the front objective lens is shown in Figure 5, which consists of 10 spherical lenses. The total length and back focal length are 85 and $11.7 \mathrm{~mm}$, respectively. Figure 6 shows the modulation transfer function (MTF) of the optimized front objective lens at $77 \mathrm{LP} / \mathrm{mm}$, and the MTFs of all bands are greater than 0.32 .

Table 4. Optical parameters of the objective.

\begin{tabular}{cc}
\hline Parameters & Value \\
\hline Focal length & $13 \mathrm{~mm}$ \\
Relative aperture & $1 / 4.5$ \\
FOV & $54^{\circ}$ \\
Spectral range & $400 \sim 1000 \mathrm{~nm}$ \\
\hline
\end{tabular}

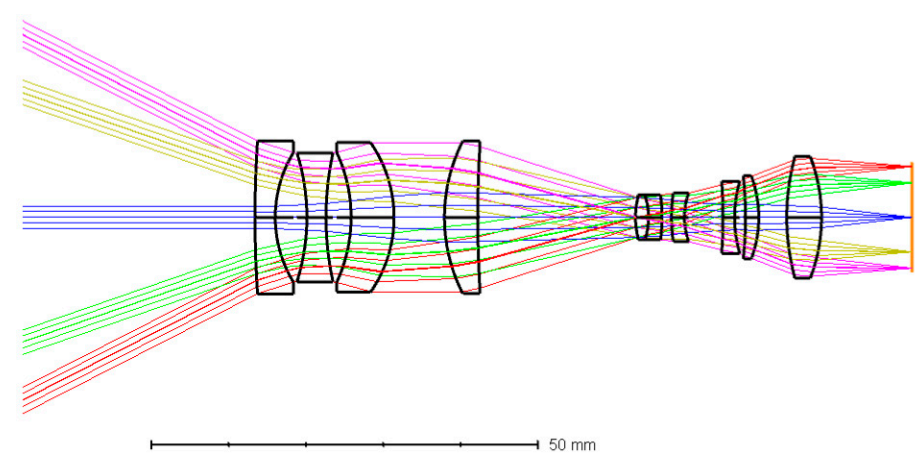

Figure 5. The layout of the objective lens.

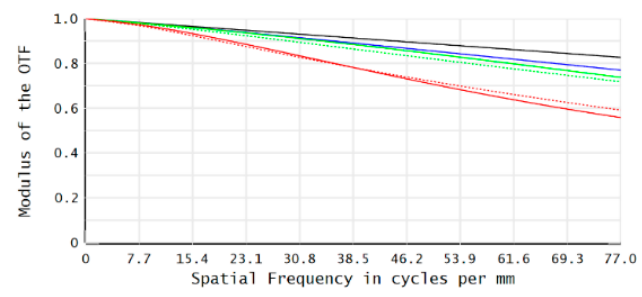

(a)

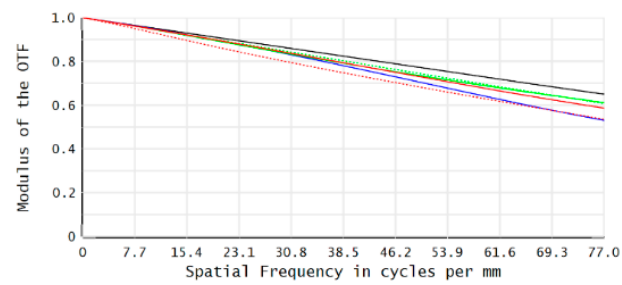

(c)

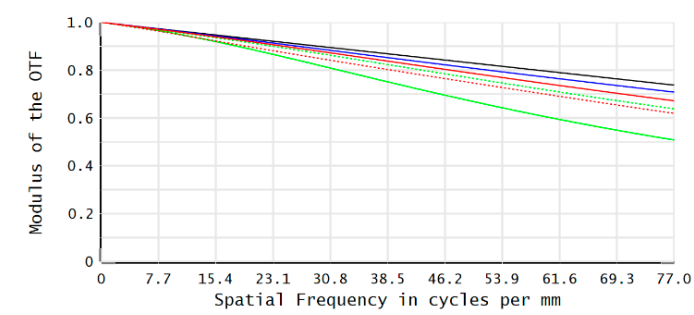

(b)

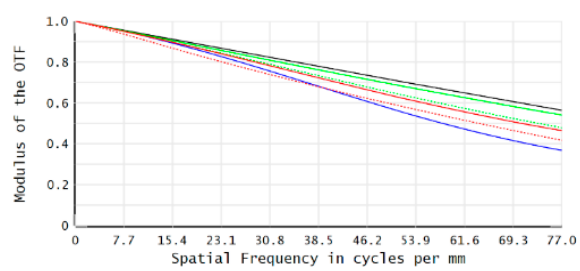

(d)

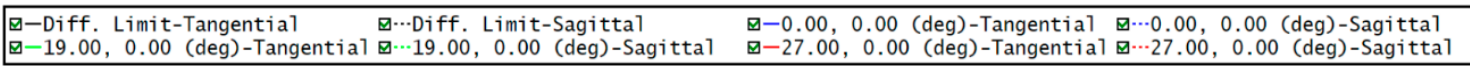

Figure 6. Modulation transfer function (MTF) of the front objective lens for (a) $400 \mathrm{~nm}$, (b) $600 \mathrm{~nm}$, (c) $800 \mathrm{~nm}$, and (d) $1000 \mathrm{~nm}$. 
The field curvature and distortion of the system are shown in Figure 7, and the maximum relative distortion is less than $1.2 \%$. The relative illumination is shown in Figure 8, and we can see that the illumination of the edge FOV is about $70 \%$ of the center FOV.
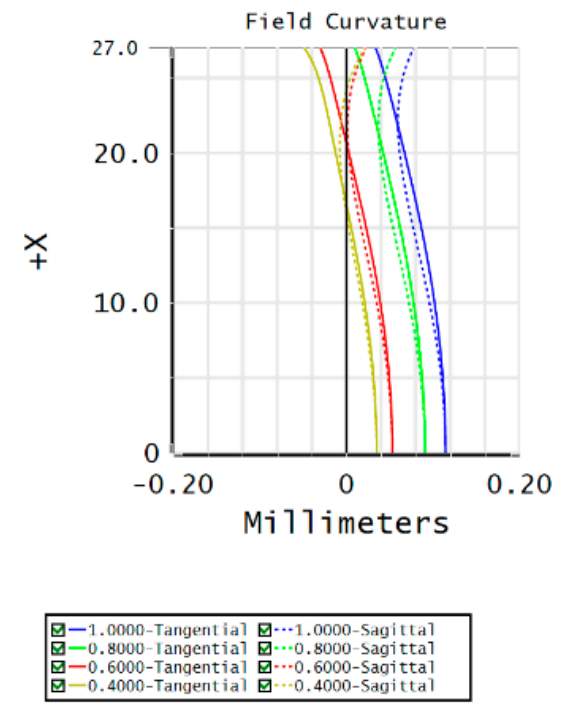

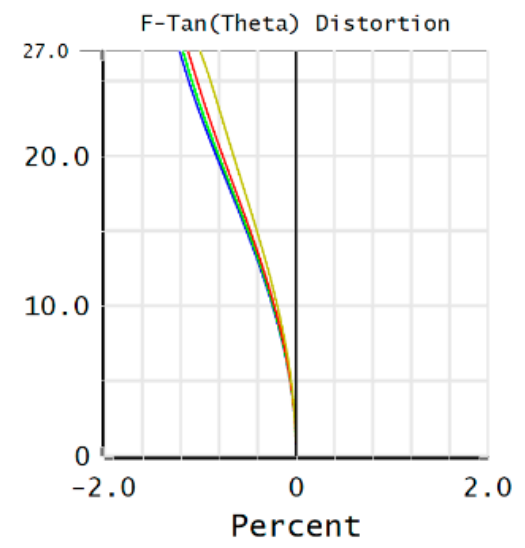

曰-1.0000 घ-0.8000 घ-0.6000日-0.4000

Figure 7. The field curvature and distortion of the objective lens.

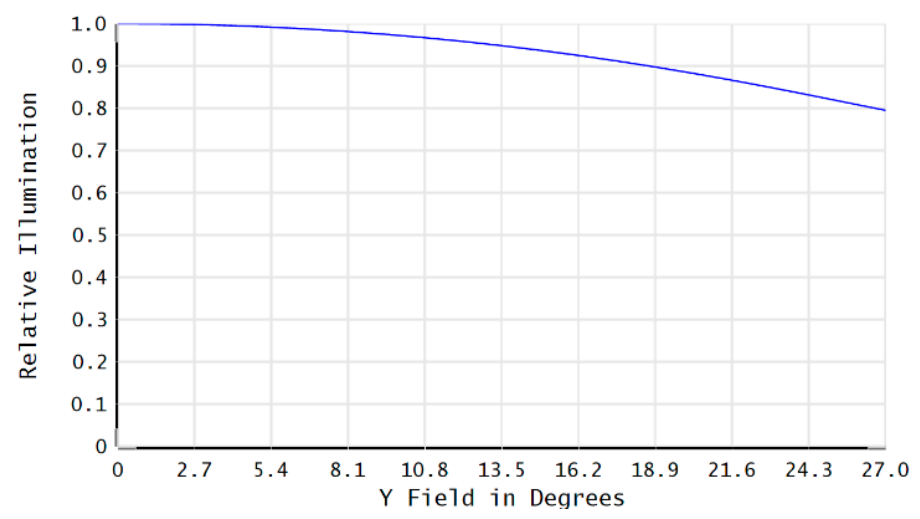

Figure 8. The relative illumination of the objective lens.

\section{Design of the Offner Spectrometer}

The Offner spectrometer is a concentric three-reflection optical system, which was developed from a reflective Offner relay optical system. The Offner spectrometer with convex spherical grating consists of three mirrors, and the second mirror is a convex spherical grating. It has a small volume and negligible spectral "smile" and "keystone" distortions. Therefore, this design adopts the Offner configuration with convex spherical grating. The specific parameters of the Offner spectrometer are shown in Table 5.

Table 5. Offner spectrometer parameter index.

\begin{tabular}{cc}
\hline Parameters & Value \\
\hline Working wavelength $(\mathrm{nm})$ & $400 \sim 1000$ \\
Slit length $(\mathrm{mm})$ & 13.5 \\
Slit image dispersion width $(\mathrm{mm})$ & 2.6 \\
Object space NA & 0.11 \\
\hline
\end{tabular}


The designed Offner spectrometer is shown in Figure 9. The first mirror has the same radius of curvature as the third mirror, and the second mirror is a convex spherical grating, whose frequency is $102 \mathrm{LP} / \mathrm{mm}$. Since the grating is used as the dispersive element, there is interference with the second-order diffracted light, and a cut-off filter should be used to avoid interference.

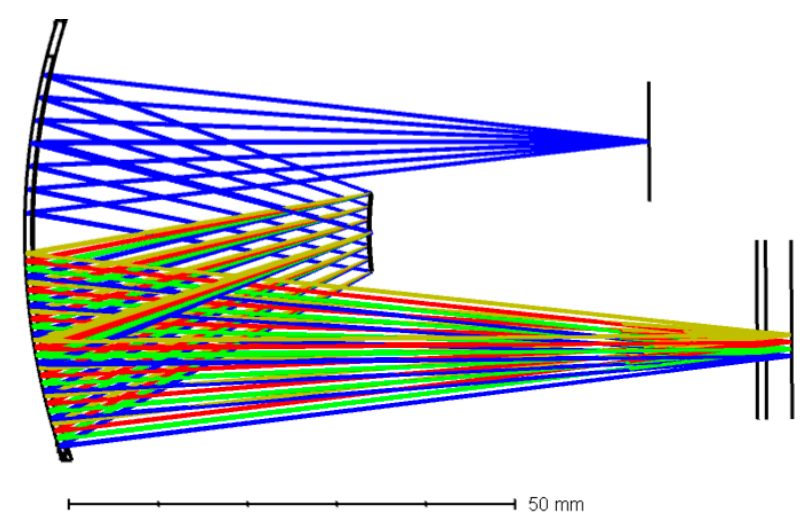

Figure 9. Configuration of the Offner spectrometer.

The MTFs of the Offner spectrometer at different wavelengths $(400 \mathrm{~nm}, 600 \mathrm{~nm}, 800 \mathrm{~nm}$, and $1000 \mathrm{~nm}$ ) are shown in Figure 10. It can be seen that the MTFs in all spectral bands are greater than 0.45 , which is close to the diffraction limit.

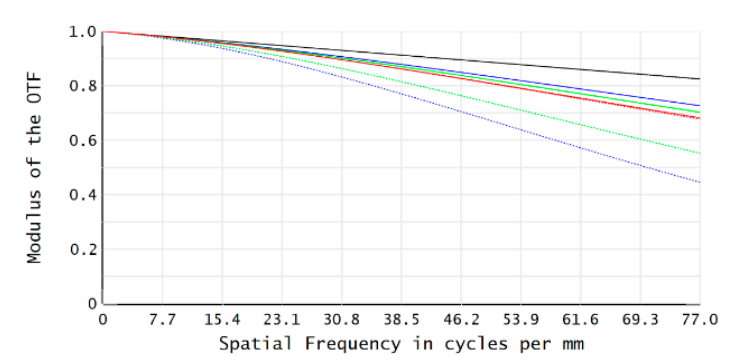

(a)

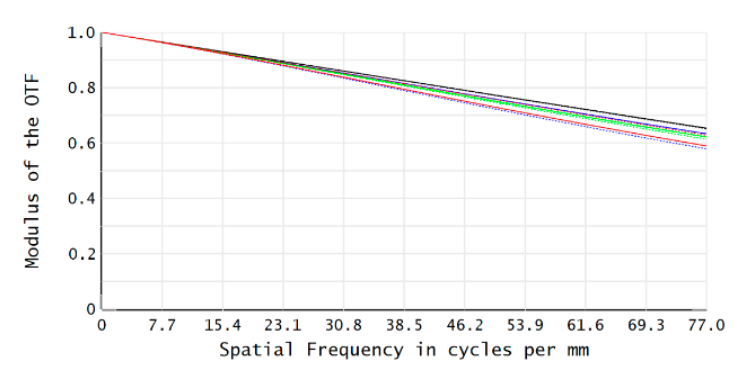

(c)

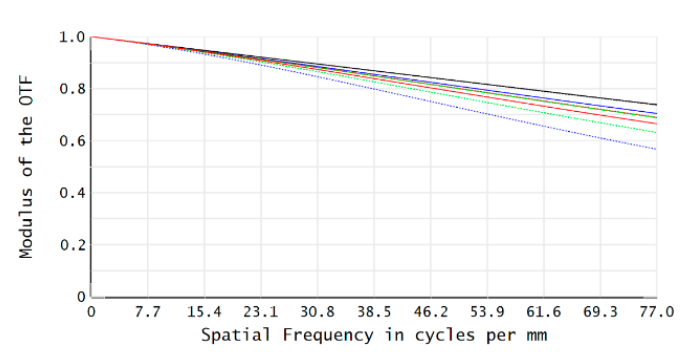

(b)

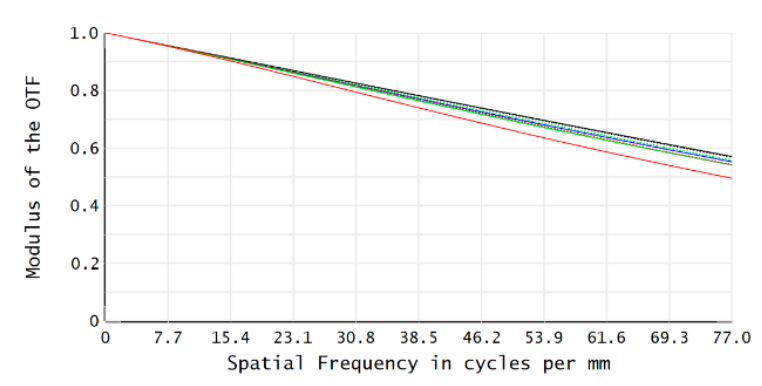

(d)

Figure 10. MTF of the Offner spectrometer (a) $400 \mathrm{~nm}$; (b) $600 \mathrm{~nm}$; (c) $800 \mathrm{~nm}$; (d) $1000 \mathrm{~nm}$.

For spectrometers, the dispersion image of the slit will cause spectral "smile" and "keystone" distortions. The "smile" distortion (sometimes called spectral line curvature or slit curvature), which refers to a curvature of the monochromatic image of the slit in the spectral dimension, leads to the misregistration of the sensor pixels across the FOV of the spectrometer in the spectral dimension. On the other hand, the "keystone" distortion, which refers to variations in the slit magnification with the wavelength, leads to interband spatial misregistration in the spectral dimension [1]. After 
optimization, the maximum "keystone" distortion and spectral line curvature are 8 and $19 \mu \mathrm{m}$, respectively, which could be improved by spectral calibration.

\section{Integrated System and Image Quality Evaluation}

\subsection{Integrated System}

The front objective lens and the Offner spectrometer are combined as shown in Figure 11. The overall optical system has a volume of $120 \times 50 \times 90 \mathrm{~mm}$.

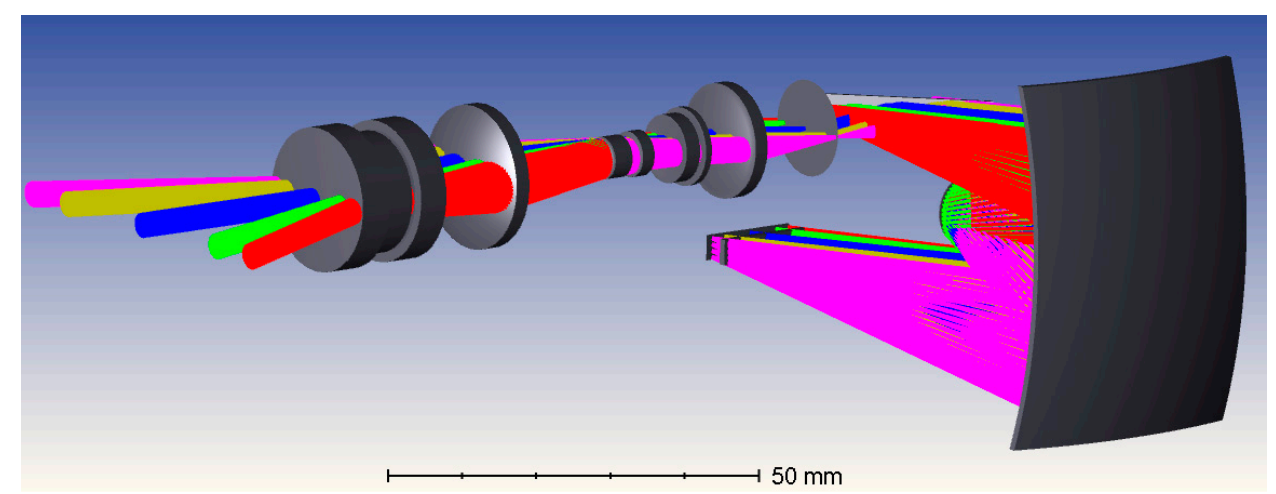

Figure 11. Integrated configuration of the spectrometer.

\subsection{Image Quality Evaluation}

The MTFs of the combined system are shown in Figure 12. We can see that the MTFs at the Nyquist frequency are all greater than 0.4.

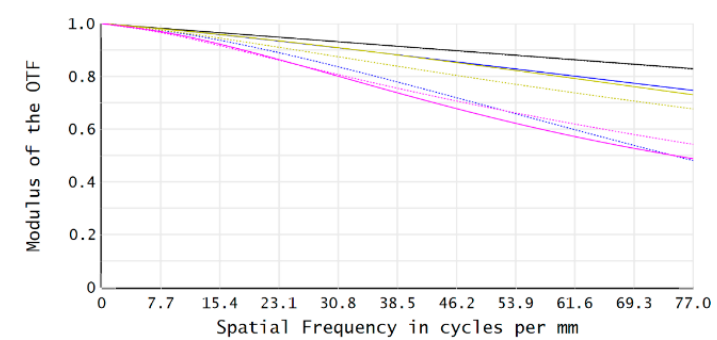

(a)

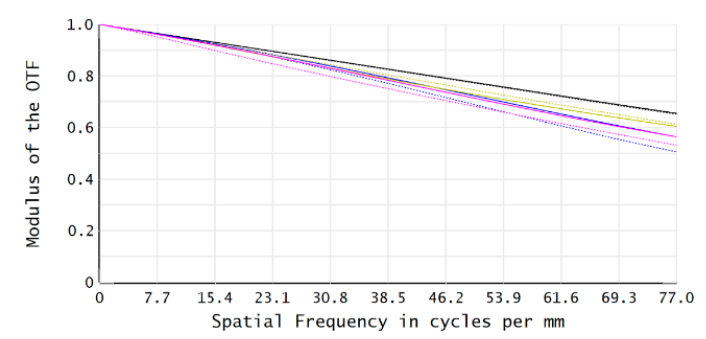

(c)

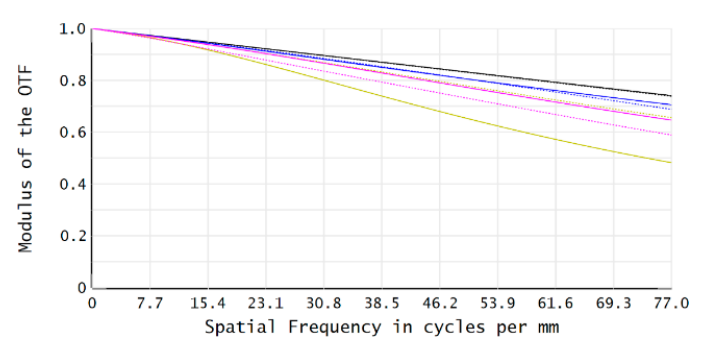

(b)

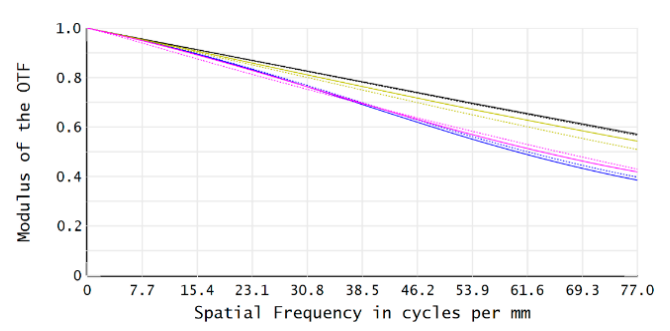

(d)

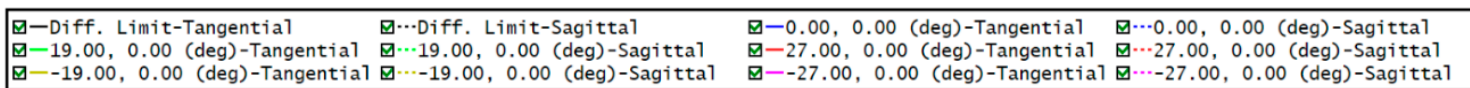

Figure 12. MTF of the integrated system (a) $400 \mathrm{~nm}$; (b) $600 \mathrm{~nm}$; (c) $800 \mathrm{~nm}$; (d) $1000 \mathrm{~nm}$. 


\section{Optical-Mechanical Design}

In order to adapt to the UAV platform, the spectrometer requires a compact structure, strong rigidity, and high thermal stability. From Table 1, the total weight of the spectrometer needs to be less than $3 \mathrm{~kg}$, so we give a preliminary optical-mechanical design scheme in this paper. All the lenses in the objective are assembled into two lens barrels, and the Offner spectrometer is in a frame structure. To improve the environmental adaptability, all structural parts can be made of aluminum alloy, while the optical components of the spectrometer, such as mirrors and grating, are made of aluminum-based materials. This design takes this approach to the selection of the mechanical and optical materials.

\subsection{Optical-Mechanical Design of the Objective Lens}

The objective lens consists of 10 lenses, a plane mirror, and a slit. When designing the optical-mechanical structure, all components are installed in two lens barrels, as shown in Figure 13. Lens barrel 1 contains four lenses, lens barrel 2 contains six lenses, and the distance between the lenses is guaranteed by spacers.

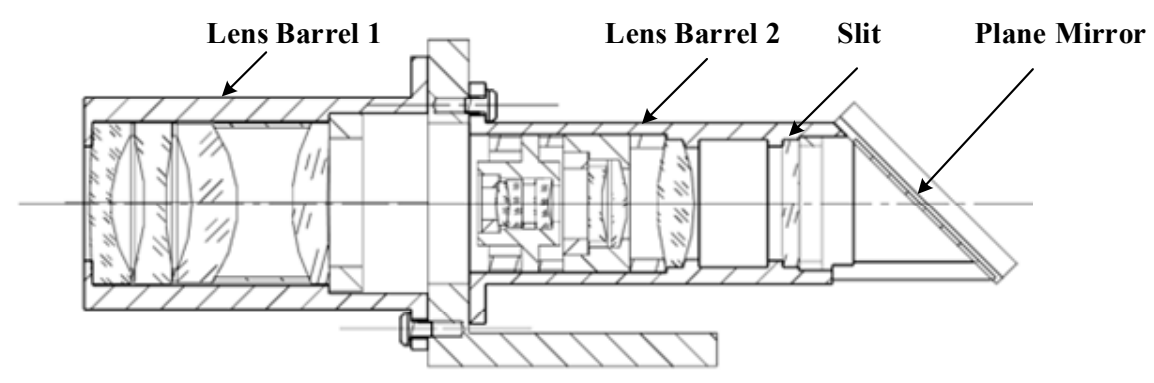

Figure 13. Optical-mechanical structure of the objective lens.

\subsection{Optical-Mechanical Design for the Combined System}

The Offner spectrometer comprises a concave mirror, a convex grating, and a sensor. All of the elements are assembled in a frame structure that is connected to the objective lens with an L-shaped bent plate, as shown in Figure 14. The total weight of the system is approximately $2.9 \mathrm{~kg}$ with a volume smaller than $130 \times 80 \times 120 \mathrm{~mm}$, which meets the technical requirements.

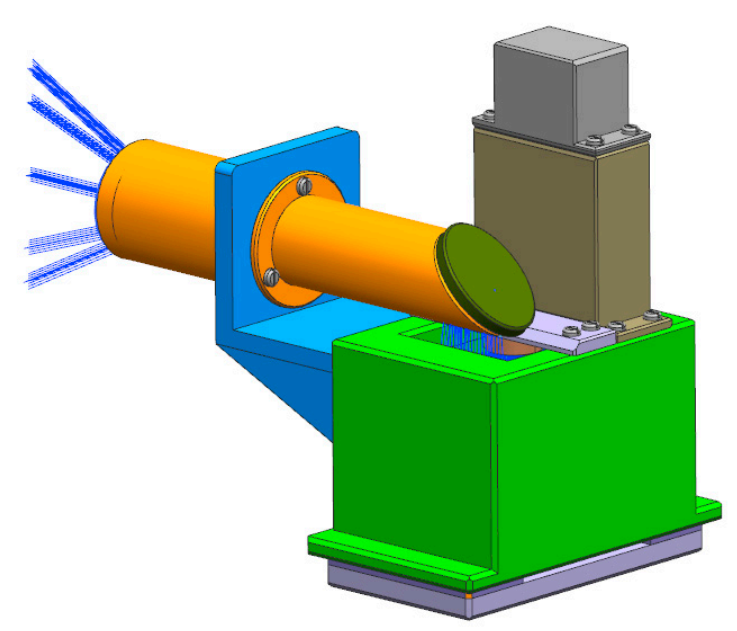

Figure 14. Integrated layout of the spectrometer. 


\section{Conclusions}

Based on the parameters of the UAV platform in Section 2.1 and the small commercial spectrometers in Section 1, a miniaturized wide-angle airborne imaging spectrometer was designed with a spectral range of $400 \sim 1000 \mathrm{~nm}$ and spectral resolution of $15 \mathrm{~nm}$. The optical system parameters were calculated based on the spectrometer specifications, and the SNR of the system was also analyzed. The front inverted telephoto objective lens and Offner spectrometer of the airborne push-broom spectrometer were completed with good performance. The objective's full $F O V$ is $54^{\circ}$ with a relative aperture of $1 / 4.5$. The grating frequency in the Offner spectrometer is $102 \mathrm{LP} / \mathrm{mm}$, the slit length is $13.5 \mathrm{~mm}$, and the dispersion width is $2.6 \mathrm{~mm}$. The MTF of the integrated system is greater than 0.4 at the Nyquist frequency in the spectral range, and the maximum "keystone" and spectral "smile" are $8 \mu \mathrm{m}$ and $19 \mu \mathrm{m}$, respectively. To estimate the volume and weight of the spectrometer, a preliminary optical-mechanical design was also developed. The entire spectrometer has a volume of $130 \times 80 \times 120 \mathrm{~mm}$, and the weight is less than $3 \mathrm{~kg}$. The results show that the spectrometer is compact with a wide $F O V$, which meets the needs of UAV platforms for miniaturized spectrometers in our engineering project.

Author Contributions: Funding acquisition, Y.F.; Investigation, Y.W.; Methodology, Z.G.; Software, X.M.; Writing-original draft, Y.W.; Writing-review \& editing, Y.W., Z.G., and L.Z. All authors have read and agreed to the published version of the manuscript.

Funding: This research was funded by the Excellent Young Talent Fund of the Department of Science and Technology of Jilin Province, grant number 20190103046JH.

Conflicts of Interest: The authors declare no conflicts of interest.

\section{References}

1. Yuan, L.; Xie, J.; He, Z.; Wang, Y.; Wang, J. Optical design and evaluation of airborne prism-grating imaging spectrometer. Opt. Express 2019, 27, 17686-17700. [CrossRef] [PubMed]

2. Goetz, A.F. Three decades of hyperspectral remote sensing of the Earth: A personal view. Remote Sens. Environ. 2009, 113, S5-S16. [CrossRef]

3. Mouroulis, P.Z.; Sellar, R.G.; Wilson, D.W.; Shea, J.J.; Green, R.O. Optical design of a compact imaging spectrometer for planetary mineralogy. Opt. Eng. 2007, 46, 063001. [CrossRef]

4. Kumar, K.A.; Thapa, N.; Kuriakose, S.A. Advances in spaceborne hyperspectral imaging systems. Curr. Sci. 2015, 108, 826.

5. Mouroulis, P.; Green, R.O. Review of high fidelity imaging spectrometer design for remote sensing. Opt. Eng. 2018, 57, 040901. [CrossRef]

6. Bender, H.A.; Mouroulis, P.Z.; Green, R.O.; Wilson, D.W. Optical design, performance, and tolerancing of next-generation airborne imaging spectrometers. Proc. SPIE 2010, 7812, 181-189.

7. Warren, C.P.; Even, D.; Pfister, W.; Nakanishi, K.; Velasco, A.; Breitwieser, D.; Yee, S.; Naungayan, J. Miniaturized visible near-infrared hyperspectral imager for remote-sensing applications. Opt. Eng. 2012, 51, 111720-111721. [CrossRef]

8. Baohua, W.; Ningjuan, R.; Chongling, G.; Yuanyuan, W.; Xiaoming, Z. Optical System Design of Airborne Light and Compact High Resolution Imaging Spectrometer. Acta Opt. Sin. 2015, 35, 1022001. [CrossRef]

9. Liyin, Y.; Jianan, X.; Jia, H.; Gang, L. Optical design of compact infrared imaging spectrometer. Infrared Laser Eng. 2018, 47, 418001. [CrossRef]

10. Sigernes, F.; Fortuna, J.; Grøtte, M.E.; Syrjäsuo, M.; Storvold, R.; Johansen, T.A. Do it yourself hyperspectral imager for handheld to airborne operations. Opt. Express 2018, 26, 6021. [CrossRef] [PubMed]

11. Kwo, D.; Lawrence, G.; Chrisp, M. Design of A Grating Spectrometer From A 1:1 Offner Mirror System. Proc. SPIE 1987, 818, 275-281.

12. Lobb, D.R. Theory of concentric designs for grating spectrometers. Appl. Opt. 1994, 33, 2648-2658. [CrossRef] [PubMed]

13. Lobb, D.R. Imaging spectrometers using concentric optics. Proc. SPIE 1997, 3118, 339-347.

14. Mouroulis, P.; Wilson, D.W.; Maker, P.D.; Muller, R.E. Convex grating types for concentric imaging spectrometers. Appl. Opt. 1998, 37, 7200-7208. [CrossRef] [PubMed] 
15. Prietoblanco, X.; Monteroorille, C.; Couce, B.; La Fuente, R.D. Analytical design of an Offner imaging spectrometer. Opt. Express 2006, 14, 9156-9168. [CrossRef] [PubMed]

16. Kim, S.H.; Kong, H.J.; Lee, J.U.; Lee, J.H.; Lee, J.H. Design and construction of an Offner spectrometer based on geometrical analysis of ring fields. Rev. Sci. Instrum. 2014, 85, 083108. [CrossRef] [PubMed]

17. Zhu, J.; Shen, W. Analytical design of athermal ultra-compact concentric catadioptric imaging spectrometer. Opt. Express 2019, 27, 31094-31109. [CrossRef] [PubMed]

18. Sellar, R.G.; Boreman, G.D.; Kirkland, L.E. Comparison of signal collection abilities of different classes of imaging spectrometers. Proc. SPIE 2002, 4816, 389-396.

19. Sellar, R.G.; Boreman, G.D. Comparison of relative signal-to-noise ratios of different classes of imaging spectrometer. Appl. Optics 2005, 44, 1614-1624. [CrossRef] [PubMed]

20. Fisher, J.; Welch, W.C. Survey and analysis of fore-optics for hyperspectral imaging systems. Proc. SPIE 2006, 6206, 62062R.

(C) 2020 by the authors. Licensee MDPI, Basel, Switzerland. This article is an open access article distributed under the terms and conditions of the Creative Commons Attribution (CC BY) license (http://creativecommons.org/licenses/by/4.0/). 